
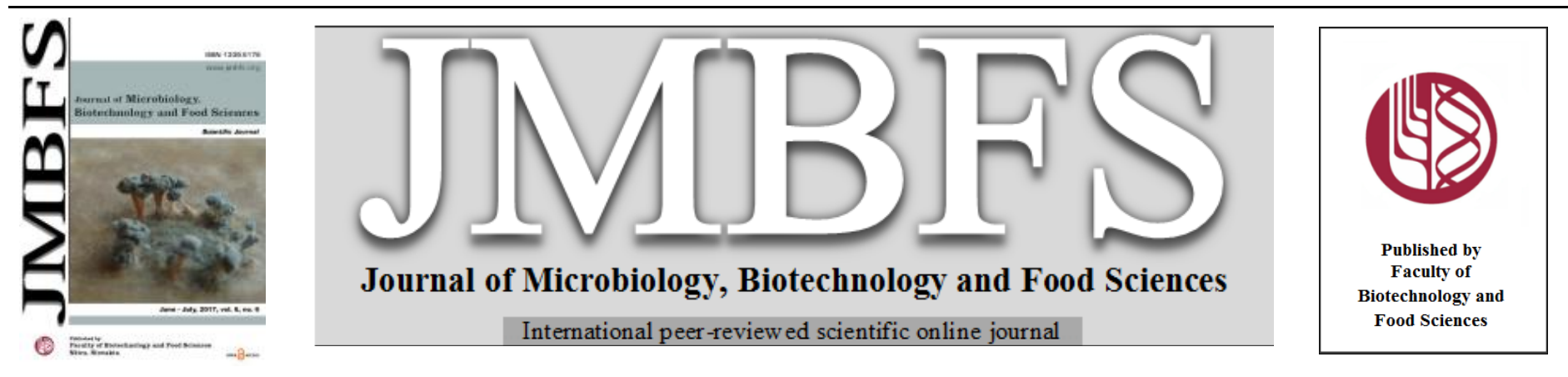

\title{
THE IN VITRO EFFECT OF ELDERBERRY (SAMBUCUS NIGRA) EXTRACT ON THE ACTIVITY AND OXIDATIVE PROFILE OF BOVINE SPERMATOZOA
}

\author{
Abzal Abdramanov ${ }^{l}$, Peter Massanyi ${ }^{2}$, Nurzhan Sarsembayeva ${ }^{1}$, Altay Usenbayev ${ }^{l}$, Jahongir Alimov $^{3}$, Eva Tvrdá $^{* 2}$
}

Address(es): MSc. Eva Tvrdá, PhD.,

${ }^{1}$ Kazakh National Agrarian University, Abai street 8, 050010 Almaty city, Kazakhstan.

${ }^{2}$ Slovak University of Agriculture, Tr. A. Hlinku 2, 94976 Nitra, Slovakia.

${ }^{3}$ Gulistan State University, $4^{\text {th }}$ Microrayon, Guliston 120100 , Syrdarya, Uzbekistan.

*Corresponding author: evina.tvrda@gmail.com

doi: $\underline{10.15414 / j m b f s .2017 .6 .6 .1319-1322}$

\section{ARTICLE INFO}

Received 15. 3. 2017

Revised 19. 4. 2017

Accepted 10. 5. 2017

Published 1. 6. 2017

Regular article

open $\bigodot_{\text {access }}$

\begin{abstract}
The paper presents the overall results and experimental details of the in vitro assessment of the elderberry (Sambucus nigra) extract on the motility, viability and reactive oxygen species (ROS) production of bovine spermatozoa in different time periods (0, 2, 6 and 24 hours). Sambucus nigra is often used for medicinal purposes throughout the world. Modern research reveals that Sambucus nigra extracts may have anti-inflammatory, antiviral, anticancer and antioxidant properties, because of a high content of biologically active components. Spermatozoa motility was assessed using the Computer-assisted sperm analysis (CASA) system. Cell viability was examined using the metabolic activity MTT assay and ROS generation was quantified using luminometry. The CASA analysis revealed that the motility in the experimental groups supplemented with 100,50 and $1 \mu \mathrm{g} / \mathrm{mL}$ elderberry extract was lower in comparison with other samples. The experiment showed that the elderberry extract had a considerable in vitro effect on the sperm motility, vitality and oxidative profile. The ROS production as well as the CASA assessment proved that the optimal concentration of both extracts was 10 $\mu \mathrm{g} / \mathrm{mL}$ in every time with statistically significant results. The MTT test showed a statistically significant increase of mitochondrial at all time periods with $10 \mu \mathrm{g} / \mathrm{mL}$ elderberry extract when compared to the control group. When lower concentrations of the elderberry extract were used ( 5 and $1 \mu \mathrm{g} / \mathrm{mL}$ ), the mitochondrial activity was higher than in the control group but lower than in the group supplemented with $10 \mu \mathrm{g} / \mathrm{mL}$ of the extract. In these groups this indicator increased maximally after $24 \mathrm{~h}$. The findings of the present study indicate that Sambucus nigra extract possesses activity promoting properties on bovine spermatozoa at 10 and $5 \mu \mathrm{g} / \mathrm{mL}$.
\end{abstract}

Keywords: Elderberry, Sambucus nigra, spermatozoa, bull, motility, mitochondrial activity, reactive oxygen species

\section{INTRODUCTION}

Several commonly used plants have been reported to affect male reproductive functions in wildlife and humans. The effects observed with most of the plant and plant-based products have been attributed to a wide variety of properties of one or more active compounds present in ethnopharmacologically important medicinal herbs (D'Cruz et al., 2010). Evaluation of herbs has been in progress worldwide for several decades to identify effective and safe substances for fertility regulation. This approach proved to be a good alternative to synthetic drugs as the chemicals of plant origin have limited side effects. Various medicinal plants extracts were investigated for their fertility-related activity both in male and female animal models (Sharma et al., 2013).

Sambucus nigra Linn, frequently known as 'Sweet elder' belongs to family Caprifoliaceae. Sambucus species are being investigated for their potential health benefits. It is one of the most attractive trees being put to some useful purpose in Ayurveda, homeopathic medicine and has become a cynosure to modern treatment options. The plant is highly used traditionally in curing diverse disorders. Commonly it is used as an astringent, antiviral and diuretic. The antioxidant activity of elderberry extracts has been evaluated before, and it is estimated to be similar to that of black raspberries, blackberries, and other darkfleshed small fruit Elderberries contain flavonoids (flavone, flavonone, isoflavone derivatives and anthocyanins), which are reported to possess antioxidant activity and to protect against oxidative stressors, such as hydrogen peroxide, 2-amidinopropane, dihydrochloride (AAPH), ferrous sulfate, and ascorbic acid (Kaur et al., 2014).

Sambucus nigra L. has been found to be effective against some important pathogenic microorganisms involved in wounds, bums, skin infections, enteritis, typhoid and candidiasis. Thus, the extract of Sambucus nigra L. berries can be used in order to treat these ailments. Elderberry extracts proved to be active against Staphylococcus aureus and Bacillus subtilis at low concentration and against $C$. albicans at very low concentrations. It is however, more effective against Pseudomonas aeruginosa, Escherichia coli and Salmonella typhi. Elderberry can be used in treating diseases caused by selected test organisms. It also contains sterols, tannins, essential oils and can readily be considered as a healthy food. It can also be used as a strong food preservative (Mohammadsadeghi et al., 2013). Sambucus nigra fruit extract powder has a very high in vitro antioxidant activity and no mutagenic effects at low concentrations (Bratu et al., 2012).

This study investigated the in vitro effects of the Sambucus nigra extract on the motility, viability and oxidative profile of bovine spermatozoa.

\section{MATERIAL AND METHODS}

\section{Plant Material}

Sambucus nigra berries were obtained from the Botanical Garden at the Slovak University of Agriculture in Nitra. After drying, the plant tissues were crushed, weighed and soaked in ethanol p.a. (96\%, Centralchem, Bratislava, Slovak Republic) during two weeks at room temperature in the dark. Exposure to sunlight was avoided to prevent the degradation of active components. The ethanolic plant extracts were subjected to evaporation under reduced pressure at $40{ }^{\circ} \mathrm{C}$ in order to remove any residual ethanol (Stuart RE300DB rotary evaporator, Bibby Scientific Limited, UK, and vacuum pump KNF N838.1.2KT.45.18, KNF, Germany). Crude plant extracts were dissolved in DMSO (Dimethyl sulfoxide; Sigma-Aldrich, St. Louis, USA) to equal 100.4 $\mathrm{mg} / \mathrm{mL}$ as a stock solution.

\section{Sample Collection and Processing}

Bovine semen samples were obtained from 10 adult Holstein breeding bulls (Slovak Biological Services, Nitra, Slovak Republic). The animals were of similar age and were kept under uniform feeding and housing conditions. Two 
samples were obtained from each bull on a regular collection schedule with the help of an artificial vagina. Subsequently, sperm concentration and motility was evaluated using phase contrast microscopy $(200 \mathrm{x})$. Only semen samples with a minimum $70 \%$ progressive motility were used for the experiments.

Each sample was diluted in physiological saline solution (PS; sodium chloride $0.9 \% \mathrm{w} / \mathrm{v}$; Bieffe Medital, Italia) containing different concentrations of the elderberry extract $(1,5,10,50$ and $100 \mu \mathrm{g} / \mathrm{mL})$ using a dilution ratio of $1: 40$. The samples were cultured at laboratory temperature $\left(22-25^{\circ} \mathrm{C}\right)$. The control $(\mathrm{Ctrl})$ group (medium without Sambucus nigra extract supplementation, containing $0.5 \%$ DMSO) was compared with the experimental groups.

\section{Spermatozoa Motility Analysis}

Spermatozoa motility (\%; MOT) was assessed by using the computer-aided sperm analysis (CASA, Version 14.0 TOX IVOS II.; Hamilton-Thome Biosciences, Beverly, MA, USA). Ten $\mu \mathrm{L}$ of each sample were placed into the Makler counting chamber (depth $10 \mu \mathrm{m}, 37^{\circ} \mathrm{C}$; Sefi Medical Instruments. Haifa, Israel) and immediately assessed. Ten microscopic fields were subjected to each analysis in order to include at least 300 cells.

\section{Mitochondrial Activity (MTT Test)}

Viability of the cells exposed to Sambucus nigra was evaluated by the metabolic activity (3-(4,5-dimethylthiazol-2-yl)-2,5-diphenyltetrazolium bromide) MTT test. This colorimetric assay measures the conversion of a yellow tetrazolium salt (MTT) to blue formazan particles by mitochondrial succinate dehydrogenase of intact mitochondria within living cells. Formazan can be measured spectrophotometrically.

The MTT tetrazolium salt (Sigma-Aldrich, St. Louis, USA) was dissolved in phosphate-buffered saline (Dulbecco's PBS; Sigma-Aldrich) at $5 \mathrm{mg} / \mathrm{mL}$. A 10 $\mu \mathrm{L}$ of the solution was added to the cells (in $100 \mu \mathrm{L}$ medium per well). After $2 \mathrm{~h}$ of incubation (shaker, $37{ }^{\circ} \mathrm{C}, 95 \%$ air atmosphere, $5 \% \mathrm{C} 02$ ), the cells and the formazan crystals were dissolved in $150 \mu \mathrm{L}$ of acidified $(0.08 \mathrm{M} \mathrm{HC}$, Centralchem, Bratislava, Slovak Republic) isopropanol (Centralchem). The optical density was determined at a wavelength of $570 \mathrm{~nm}$ against $620 \mathrm{~nm}$ as reference by a microplate ELISA reader (Anthos MultiRead 400, Austria). The data were expressed as percentage of the control, set to $100 \%$ (Knazicka et al., 2012).

\section{ROS Generation}

ROS levels in samples were assessed by the chemiluminescence assay using luminol (5-amino-2, 3-dihydro-1, 4-phthalazinedione; Sigma-Aldrich) as the probe. The test samples consisted of luminol $(10 \mathrm{uL}, 5 \mathrm{mM})$ and $400 \mathrm{uL}$ of control or experimental sample. Negative controls were prepared by using $400 \mathrm{uL}$ Dulbecco's PBS (Sigma-Aldrich). Positive control included 400 uL Dulbecco's PBS and $50 \mathrm{uL}$ of hydrogen peroxide (30\%; $8.8 \mathrm{M}$; Sigma-Aldrich) in triplicates.
Chemiluminescence was measured on a 48-well plate for 15 min by using the Glomax MultiPlus Combined Spectro-Fluoro-Luminometer (Promega, Madison, WI, USA). The results were expressed as relative light units (RLU)/sec/10 ${ }^{6} \mathrm{sperm}$ (Kashou et al., 2013)

\section{Statistical Analysis}

Statistical analysis was carried out by using the GraphPad Prism program (version 3.02 for Windows; GraphPad Software, La Jolla California USA www.graphpad.com). Descriptive statistical characteristics (mean, standard error) were evaluated at first. As we focused to study the impact of different elderberry concentrations on the spermatozoa activity (experimental groups) in comparison to the control at a specific time frame, thus taking one factor into consideration, one-way ANOVA was used for specific statistical evaluations. Dunnett test was used as a follow-up test to ANOVA, based on a comparison of every mean to a control mean, and computing a confidence interval for the difference between the two means. The level of significance was set at *** $(\mathrm{P}<0.001)$; ** $(\mathrm{P}<0.01)$; * $(\mathrm{P}<0.05)$.

\section{RESULTS AND DISCUSSION}

Over the past years, natural compounds isolated from plants have emerged exhibiting a complex biological activity. Due to their broad range of effects, particularly with respect to antibacterial, anti-inflammatory protection and antioxidant mechanisms, plant extracts have attracted a widespread scientific and consumer interest (Putheti and Okigbo, 2008; Omogbadegun et al., 2011; Tohamy et al., 2012; Hamidpour et al., 2014).

The CASA assessment showed a continuous decrease of spermatozoa motility in all groups over the course of a $24 \mathrm{~h}$ in vitro culture (Table 1). The initial (Time Oh) MOT was higher in the experimental groups supplemented with 100 and 1 $\mu \mathrm{g} / \mathrm{mL}$ elderberry extract and lower in other groups with extract when compared to the control group, although without any statistical significance $(P>0.05)$. No significant differences among the control and experimental groups were recorded at Time $2 \mathrm{~h}$ : the groups supplemented with the extract at 100 and $50 \mu \mathrm{g} / \mathrm{mL}$ the MOT was lower, as at the 10,5 and $1 \mu \mathrm{g} / \mathrm{mL}$ - higher. A statistically significant motion-activating effect became visible after $6 \mathrm{~h}$ in the group supplemented with $10 \mu \mathrm{g} / \mathrm{mL}$ of the Sambucus nigra extract whereas in other groups no significant effects of the extract were observed. At the end of the experiment (Time $24 \mathrm{~h}$ ), the motility observed in the experimental groups supplemented with $1-100 \mu \mathrm{g} / \mathrm{mL}$ elderberry extract was higher in comparison with the control, but a significantly highest MOT was established at the $10 \mu \mathrm{g} / \mathrm{mL}$ concentration. Sambucus nigra concentrations ranging between $1-100 \mu \mathrm{g} / \mathrm{mL}$ had an impact of activation on the sperm MOT when compared to the control. Nevertheless a significant influence was shown with respect to the extract at a concentration of $10 \mu \mathrm{g} / \mathrm{mL}$ at all assessment periods (Table 1).

Table 1 Bovine spermatozoa motility (MOT, \%) in the absence (Ctrl) or presence of elderberry extract during different time periods $(\mathrm{Mean} \pm \mathrm{SEM} ; \mathrm{n}=10)$

\begin{tabular}{cccccc}
\hline \multirow{2}{*}{ Time } & \multirow{2}{*}{ Ctrl } & \multicolumn{4}{c}{ Concentration of Sambucus nigra, $\boldsymbol{\mu g} / \mathbf{m L}$} \\
\cline { 2 - 6 } & & $\mathbf{1 0 0}$ & $\mathbf{5 0}$ & $\mathbf{1 0}$ & $\mathbf{5}$ \\
\hline $\mathbf{0 h}$ & $74.75 \pm 7.21$ & $78.25 \pm 5.80$ & $69.00 \pm 1.91$ & $74.00 \pm 3.12$ & $71.00 \pm 8.18$ \\
$\mathbf{2 h}$ & $63.75 \pm 1.88$ & $58.25 \pm 1.73$ & $58.00 \pm 5.97$ & $68.75 \pm 4.87$ & $67.75 \pm 1.49$ \\
$\mathbf{6 h}$ & $51.25 \pm 2.25$ & $48.75 \pm 1.49$ & $50.75 \pm 3.80$ & $60.25 \pm 2.31^{*}$ & $50.00 \pm 5.34$ \\
$\mathbf{2 4 h}$ & $20.25 \pm 6.80$ & $20.50 \pm 4.87$ & $24.75 \pm 1.23$ & $31.00 \pm 1.62^{*}$ & $27.00 \pm 2.31$ \\
\hline${ }^{*} \mathrm{P}<0.05 ;{ }^{* *} \mathrm{P}<0.01 ;{ }^{* * *} \mathrm{P}<0.001$ & & & &
\end{tabular}

Progressive motility of control and experimental groups at 0 hours of experimental period, with different concentrations of the elderberry extract, did not exhibit significant differences. At $2 \mathrm{~h}$ of experimental period the higher concentration of Sambucus nigra extract with 100 and $50 \mu \mathrm{g} / \mathrm{mL}$ decreased spermatozoa progressive motility (PRG, \%). After 6 and 24 hours of experimental periods showed, that the progressive motility of the control and experimental samples with the 100,50 and $1 \mu \mathrm{g} / \mathrm{mL}$ of the elderberry extract was lower, compared to 10 and $5 \mu \mathrm{g} / \mathrm{mL}$ (Table 2).

Table 2 Bovine spermatozoa progressive motility (PRG, \%) in the absence (Ctrl) or presence of Sambucus nigra extract during different time periods (Mean \pm SEM; $n=10$ )

\begin{tabular}{cccccc}
\hline \multirow{2}{*}{ Time } & \multirow{2}{*}{ trl } & \multicolumn{4}{c}{ Concentration of Sambucus nigra, $\boldsymbol{\mu g} / \mathbf{m L}$} \\
\cline { 2 - 6 } & & $\mathbf{1 0 0}$ & $\mathbf{5 0}$ & $\mathbf{1 0}$ & $\mathbf{5}$ \\
\hline $\mathbf{0 h}$ & $46.75 \pm 4.79$ & $44.00 \pm 1.87$ & $48.50 \pm 3.86$ & $48.00 \pm 5.80$ & $48.00 \pm 3.10$ \\
$\mathbf{2 h}$ & $45.75 \pm 1.76$ & $29.00 \pm 5.76^{*}$ & $34.25 \pm 3.87$ & $48.00 \pm 6.80$ & $46.00 \pm 3.43$ \\
$\mathbf{6 h}$ & $23.00 \pm 1.46$ & $17.25 \pm 1.39^{*}$ & $23.00 \pm 1.37$ & $31.50 \pm 1.74^{*}$ & $28.50 \pm 2.35$ \\
$\mathbf{2 4 h}$ & $3.50 \pm 0.46$ & $1.75 \pm 0.11^{*}$ & $1.25 \pm 0.34$ & $6.00 \pm 0.33^{*}$ & $6.20 \pm 0.87 *$ \\
${ }^{*} \mathrm{P}<0.05 ;{ }^{* *} \mathrm{P}<0.01 ;{ }^{* * *} \mathrm{P}<0.001$ & & & & &
\end{tabular}

According to the MTT assay, an instant Sambucus nigra supplementation (Time $0 \mathrm{~h}$ ) had different effects on the sperm mitochondrial activity in any of the experimental groups (Fig. 1). It was established that $100 \mu \mathrm{g} / \mathrm{mL}$ extract had no specific impact on the mitochondrial activity: at 0 and $2 \mathrm{~h}$ it was lower and through 6 and $24 \mathrm{~h}$ it was almost equal to the control group. Impact of the 50 $\mu \mathrm{g} / \mathrm{mL}$ concentration to the sperm was analogical with a higher activation at 2 and $6 \mathrm{~h}$ (Fig. 1). A statistically significant increase of mitochondrial activity was observed at all time periods with $10 \mu \mathrm{g} / \mathrm{mL}$ elderberry extract when compared to the control group. When lower concentrations of the elderberry extract were used ( 5 and $1 \mu \mathrm{g} / \mathrm{mL}$ ) the mitochondrial activity was higher than in the control group but lower than in the group supplemented with $10 \mu \mathrm{g} / \mathrm{mL}$ of the plant extract (Fig. 1). In these groups this indicator increased maximally after $24 \mathrm{~h}$ (Fig. 1). 
From these results we may hypothesize that the $10 \mu \mathrm{g} / \mathrm{mL}$ of the elderberry extract have a direct activating effect on the mitochondrial energy metabolism, a crucial factor supporting key spermatozoa motion. Activation of the mitochondrial function can increase sperm motility, and subsequently male fertilizing capacity.
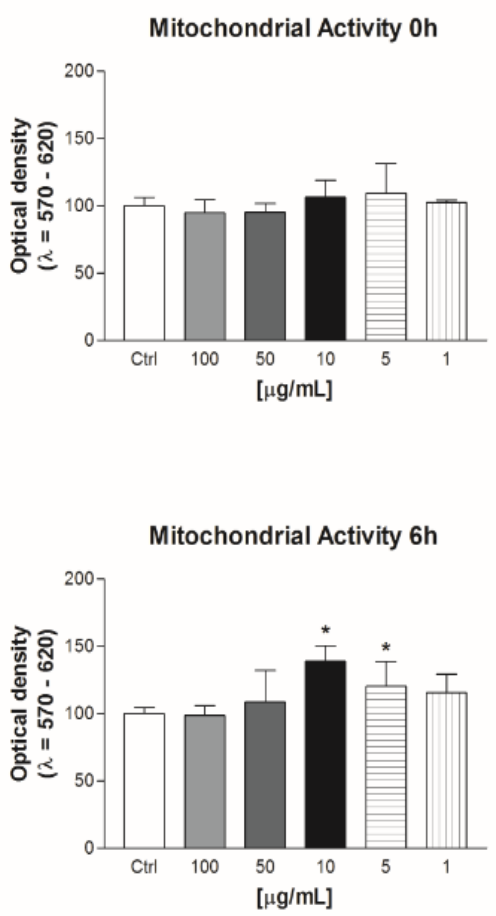

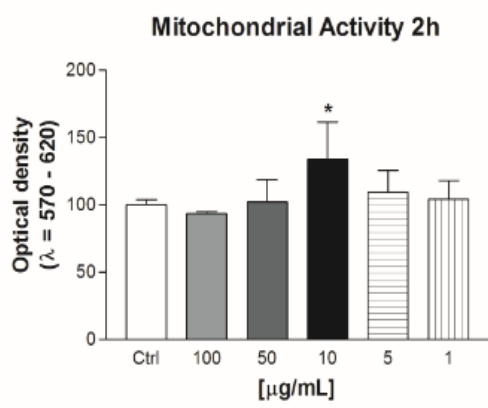

Mitochondrial Activity 24h

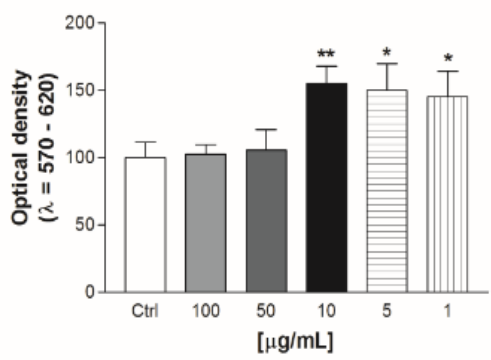

Figure 1 Mitochondrial activity of bovine spermatozoa (\%) in the absence (Ctrl) or presence of the Sambucus nigra extract in different time periods. MEAN $\pm \mathrm{SEM} ; * *(\mathrm{P}<0.01) ; *(\mathrm{P}<0.05)$

Oxidative stress (OS) has become one of the leading causes related to the loss of viable spermatozoa during cryopreservation. ROS over generation is nowadays accepted as a notable side effect of in vitro processing and handling protocols of semen, leading to major disruptions in the cellular oxidative metabolism. The resulting OS may subsequently lead to irreversible alterations of membrane structures via LPO, as well as oxidative degradation of proteins or DNA, followed by apoptotic activation (Ball, 2008).
Our investigation revealed that the lowest ROS production was observed in the group with $10 \mu \mathrm{g} / \mathrm{mL}$ extract, where after 2 hours cultivation with extract the ROS production was almost half of the control group $(\mathrm{P}<0.01)$. After 6 and 24 hours we could definitely confirm a significant positive antioxidant effect in this group compared with control and other experimental groups $(\mathrm{P}<0.05$ in case of $50,10$ and $5 \mu \mathrm{g} / \mathrm{mL})$.

Table 3 Reactive oxygen species production (ROS) production by bovine spermatozoa (RLU/sec/10 $10^{6}$ sperm) in the absence (Ctrl) or presence of the Sambucus nigra extract in different time periods.

\begin{tabular}{|c|c|c|c|c|c|c|}
\hline \multirow{2}{*}{ Time } & \multirow{2}{*}{ Ctrl } & \multicolumn{5}{|c|}{ Concentration of Sambucus nigra, $\mu \mathrm{g} / \mathrm{mL}$} \\
\hline & & 100 & 50 & 10 & 5 & 1 \\
\hline $\mathbf{0 h}$ & $0.92 \pm 0.03$ & $1.86 \pm 0.05$ & $1.49 \pm 0.06$ & $0.70 \pm 0.03$ & $0.61 \pm 0.02$ & $0.81 \pm 0.04$ \\
\hline $6 h$ & $1.77 \pm 0.03$ & $3.21 \pm 0.11^{* *}$ & $3.01 \pm 0.70^{*}$ & $1.22 \pm 0.17^{*}$ & $1.36 \pm 0.14$ & $1.58 \pm 0.09$ \\
\hline 24h & $3.59 \pm 0.09$ & $5.13 \pm 0.13^{* *}$ & $4.33 \pm 0.38^{*}$ & $2.26 \pm 0.52^{*}$ & $2.33 \pm 0.08^{*}$ & $2.42 \pm 0.17$ \\
\hline
\end{tabular}

(OS) oxidative stress is considered as a crucial factor among causes of male infertility's pathogenesis (Lanzafame et al., 2008; Tvrdá et al., 2011) Spermatozoa was the first type of cells to be reported as susceptible to OS. The inability to restore the damage induced by OS coupled with cell membranes rich in polyunsaturated fatty acids (PUFAs), render spermatozoa to be highly susceptible to ROS-induced damage. Subsequently, a rapid loss of intracellular ATP causes mitochondrial and axonemal damage, decreased sperm viability, and increased mid-piece sperm morphological defects, all of which contribute to a decreased sperm motility (Bansal and Bilaspuri, 2011; Gharagozloo and Aitken, 2011). OS has become a great concern for clinicians and scientists as this programmed deterioration may lead to poor fertilization and embryonic development, pregnancy loss and birth defects (Butler et al., 2002; De Iuliis et al., 2006; Tremellen, 2008; Aitken et al., 2010).

The ROS production as well as the CASA assessment proved that the optima concentration of both extracts was $10 \mu \mathrm{g} / \mathrm{mL}$ in every time with statistically significant results (Table 3). The studies of Miraj (2016) defined the beneficial activity as an antioxidant stress protector with the high antioxidant capacity, observed at very low concentrations of the elderberry extract, would be easily fulfilled without any dangers or side effects when used in small amounts Sambucus nigra is known for its medicinal use and contains anthocyanins, flavonoids and other polyphenolics. Our studies point out that maybe because of the antioxidant activity the CASA analyzes was better, while ROS decreased. Also, we can notice that antioxidants mostly reduce oxidative stress and improve sperm motility, protect spermatozoa in the seminal plasma or in spermatozoa itself to prevent oxidative damage. According to the experiment data we may suggest that low concentrations of the Sambucus nigra extract decreased activity of the mitochondrial respiratory chain of complex II, thus significantly decreasing the risk of ROS overproduction.

\section{CONCLUSION}

The results of the present study indicate that the elderberry extracts have a considerable effect on the functional activity of bovine spermatozoa. The findings of the present study clearly indicate that Sambucus nigra extract possesses motility promoting properties on bovine spermatozoa at 10 and 5 $\mu \mathrm{g} / \mathrm{mL}$ concentration. However, this study is the first laboratory based experiment. In near future more studies need to be undertaken in a similar direction to prove all the data obtained from this report.

Acknowledgments: This study was supported by the Scientific Grant Agency of the Ministry of Education of the Slovak Republic and of the Slovak Academy of Sciences VEGA Project no. 1/0039/16, by the Slovak Research and 
Development Agency Grant no. APVV-15-0544 and by the European Community Project no. 26220220180: Building Research Centre "AgroBioTech".

\section{REFERENCES}

Aitken, R.J., Baker, M.A., De Iuliis, G.N. \& Nixon, B. (2010). New insights into sperm physiology and pathology. Handbook of Experimental Pharmacology, 1989, 99-115. http://dx.doi.org/10.1007/978-3-642-02062-9 7

Ball, B.A. (2008). Oxidative stress, osmotic stress and apoptosis: impacts on sperm function and preservation in the horse. Animal Reproduction Science, 107, 257-267. http://dx.doi.org/10.1016/j.anireprosci.2008.04.014

Bansal, A.K. \& Bilaspuri, G.S. (2011). Impacts of oxidative stress and antioxidants on semen functions. Veterinary Medicine International. http://dx.doi.org/10.4061/2011/686137

Bratu, M.M, Doroftei, E., Negreanu-Pirjol, T., Hostina, C. \& Porta, S. (2012) Determination of Antioxidant Activity and Toxicity of Sambucus nigra Fruit Extract Using Alternative Methods. Food Technology and Biotechnology, 50(2), 177-182.

Butler, A., He, X., Gordon, R.E., Wu, H.S., Gatt, S. \& Schuchman, E.H. (2002) Reproductive pathology and sperm physiology in acid sphingomyelinasedeficient mice, American Journal of Pathology, 161, 1061-1075.

D'Cruz, S.C., Vaithinathan, S., Jubendradass, R. \& Mathur, P.P. (2010). Effects of plants and plant products on the testis. Asian Journal of Andrology, 12(4), 468-479. http://dx.doi.org/10.1038/aja.2010.43

De Iuliis, G.N., Wingate, J.K., Koppers, A.J., McLaughlin, E.A. \& Aitken, R.J. (2006). Definitive evidence for the nonmitochondrial production of superoxide anion by human spermatozoa. Journal of Clinical Endocrinology \& Metabolism, 91, 1968-1975.

Gharagozloo, P. \& Aitken, R.J. (2011). The role of sperm oxidative stress in male infertility and the significance of oral antioxidant therapy. Human Reproduction, 26, 1628-1640. http://dx.doi.org/10.1093/humrep/der132

Hamidpour, M., Hamidpour, R., Hamidpour, S. \& Shahlari, M. (2014). Chemistry, pharmacology, and medicinal property of sage (Salvia) to prevent and cure illnesses such as obesity, diabetes, depression, dementia, lupus, autism, heart disease, and cancer. Journal of Traditional and Complementary Medicine, 4, 8288. http://dx.doi.org/10.4103/2225-4110.130373

Kashou, A.H., Sharma, R. \& Agarwal, A. (2013). Assessment of oxidative stress in sperm and semen. Methods in Molecular Biology, 927, 351-361. http://dx.doi.org/10.1007/978-1-62703-038-0 30

Kaur, K., Kaur, R., Kaur, H. \& Kaur, S. (2014). A comprehencive review: Sambucus nigra, Linn. Biolife Journal, 2(3), 941-948.

Knazicka, Z., Tvrda, E., Bardos, L. \& Lukac N. (2012). Dose- and timedependent effect of copper ions on the viability of bull spermatozoa in different media. Journal of Environmental Science and Health, Part A, 47(9), 1294-1300. http://dx.doi.org/10.1080/10934529.2012.672135

Lanzafame, F.M., La Vignera, S., Vicari, E. \& Calogero, A.E. (2009). Oxidative stress and medical antioxidant treatment in male infertility. Reproductive Biomedicine Online, 19, 638-659. http://dx.doi.org/10.1016/j.rbmo.2009.09.014

Miraj, S. (2016). Chemical composition and pharmacological effects of Sambucus nigra. Der Pharma Chemica, 8(13), 231-234.

Mohammadsadeghi, Sh., Malekpour, A., Zahedi, S. \& Eskandari, F. (2013). The Antimicrobial Activity of Elderberry (Sambucus nigra L.) Extract Against Gram Positive Bacteria, Gram Negative Bacteria and Yeast. Research Journal of Applied Sciences, 8(4), 240-243.

Omogbadegun, Z., Uwadia, C., Ayo, C., Mbarika, V., Omoregbe, N., Otofia, E. and Chieze, F. (2011). Multimedia-based medicinal plants sustainability management system. International Journal of Computer Science, 8, 492-503.

Putheti, R. \& Okigbo, R.N. (2008). Effects of plants and medicinal plant combinations as antiinfective. African Journal of Pharmacy and Pharmacology, $2,130-135$

Sharma, R.K., Goyal, A.K. \& Bhat, R.A. (2013). Antifertility activity of plants extracts on female reproduction: a review. International Journal of Pharmacy and Biological Sciences, 3, 493-514.

Tohamy, A.A., Ibrahim, S.R. \& Abdel Moneim, A.E. (2012). Studies on the effect of Salvia aegyptiaca and Trigonella foenum graecum extracts on adult male mice. Journal of Applied Pharmaceutical Science, 2, 36-43.

Tremellen, K. (2008). Oxidative stress and male infertility - a clinica perspective, Human Reproduction Update, 14, 243-258. http://dx.doi.org/10.1093/humupd/dmn004

Tvrdá, E., Kňažická, Z., Bárdos, L., Massányi, P. \& Lukáč, N. (2011). Impact of oxidative stress on male fertility - a review. Acta Veterinaria Hungarica, 59, 465484. http://dx.doi.org/10.1556/AVet.2011.034 